\title{
Sea state and rain: A second take on dual-frequency altimetry
}

\author{
Graham D. Quartly (gdq@soc.soton.ac.uk) \\ Southampton Oceanography Centre
}

[Revised 09/02/04 for Marine Geodesy 2nd special issue on Jason Cal/Val]

\begin{abstract}
TOPEX and Jason were the first two dual-frequency altimeters in space, with both operating at $\mathrm{K}_{\mathrm{u}^{-}}$and $\mathrm{C}$-band. Each thus gives two measurements of the normalized backscatter, $\sigma^{0}$, (from which wind speed is calculated) and two estimates of wave height. Departures from a well-defined relationship between the $\mathrm{K}_{\mathrm{u}^{-}}$and $\mathrm{C}$-band $\sigma^{0}$ values give an indication of rain. This paper investigates differences between the two instruments using data from Jason's verification phase. Jason's $\mathrm{K}_{\mathrm{u}}$-band estimates of wave height are $\sim 1.8 \%$ less than TOPEX's, whereas its $\sigma^{0}$ values are higher. When these effects have been removed the root mean square (r.m.s.) mismatch between TOPEX and Jason's $\mathrm{K}_{\mathrm{u}}$-band observations is close to that for TOPEX's observations at its two frequencies, and the changes in $\sigma^{0}$ with varying wave height conditions are the same for the two altimeters. Rain flagging and quantitative estimates of rain rate are both based on the atmospheric attenuation derived from the $\sigma^{0}$ measurements at the two frequencies. The attenuation estimates of TOPEX and Jason agree very well, and a threshold of $-0.5 \mathrm{~dB}$ is effective at removing the majority of spurious data records from the Jason GDRs. In the high $\sigma^{0}$ regime, anomalous data can be cause by processes other than rain. Consequently, for these low wind conditions, neither can reliable rain detection be based on altimetry alone, nor can a generic rain flag be expected to remove all suspect data.
\end{abstract}

Keywords: dual-frequency altimetry, TOPEX, Jason, wave height, sigma0, wind speed, rainflagging, rain rate

\section{Introduction}

The TOPEX altimeter (on-board the TOPEX/Poseidon satellite launched in August 1992) was the first spaceborne altimeter to operate at two frequencies (Fu et al., 1994). Earlier instruments had operated at $\mathrm{K}_{\mathrm{u}}$-band $(\sim 13.6 \mathrm{GHz})$, but the secondary channel at $\mathrm{C}$-band $(5.3 \mathrm{GHz})$ was incorporated to help determine the ionospheric delay. Estimates of significant wave height, $\mathrm{H}_{\mathrm{s}}$, and normalised backscatter, $\sigma^{0}$, were also provided for the secondary channel, although such information was probably initially thought redundant. Over the ice-free ocean the dominant factor affecting $\sigma_{\mathrm{Ku}}^{0}$ is the wind, with many different algorithms (e.g. Witter \& Chelton, 1991) being used to convert $\sigma_{\mathrm{Ku}}^{0}$ into a local wind speed, $\mathrm{U}_{10}$. Rain will also affect $\sigma^{0}$ through attenuation of the signal (reducing $\sigma^{0}$ ) and also through damping of small-scale waves (increasing $\sigma^{0}$ ). Such effects had been noted for single frequency altimeters (Srokosz \& Guymer, 1988; Guymer et al., 1995), but it was the advent of TOPEX that led to a leap forward in altimetric rain studies (Quartly et al., 1996). This was because the attenuation effect is an order of magnitude smaller at $\mathrm{C}$-band than at $\mathrm{K}_{\mathrm{u}}$-band, such that rain-affected points did not conform to the mean $\sigma^{0} \mathrm{Ku}^{-} \sigma_{\mathrm{C}}^{0}$ relationship produced by wind alone. This was first used as a basis for rain detection (Quartly et al., 1996, Tournadre \& Morland, 1997), which could be used for flagging rain-contaminated data, and then for quantitative studies of rainfall (Quartly et al., 1999, 2000).

Jason, the successor to the TOPEX/Poseidon mission, was launched in December 2001, and placed in an orbit just ahead of TOPEX/Poseidon but following the same ground track (see Fig. 1). Jason operates at the same two frequencies as TOPEX, and thus can provide 'near simultaneous' estimates of $\mathrm{H}_{\mathrm{s}}, \sigma^{0}$ and $\Delta \sigma^{0}$ (the derived atmospheric attenuation). The Jason 'verification phase' lasted from January to August 2002, with the delay between the two satellites varying between 70 and 74 seconds. Jason and TOPEX 
are very similar in operation. The main hardware differences are that Jason was constructed with newer technology, including solid state amplifiers rather than travelling wave tubes, and is consequently lighter and requires less power than TOPEX. For TOPEX, estimation of geophysical parameters is carried out on-board and transmitted with the waveform data. Corrections are then applied to these data (Hayne et al., 1994), but it is basically the values calculated on the satellite that are distributed to users. For Jason, the waveforms are retracked on the ground using more elaborate techniques (maximum likelihood estimation) than can be implemented on the satellite.

The instantaneous altimetric footprint is a disc between 2 and $8 \mathrm{~km}$ in diameter, depending upon the wave height and the geophysical parameter being derived, and this is then smeared by the $\sim 6 \mathrm{~km}$ travelled in the nominal 1 second averaging period. Thus, although individual large waves and small scale ripples (affecting $\sigma^{0}$ ) may evolve significantly in $\sim 72 \mathrm{~s}$, there will be negligible change in a statistical average over $\sim 50 \mathrm{~km}^{2}$. Rain is known to vary on timescales much shorter than those of wind or waves, but again an average over a full altimeter footprint will typically not change much in $72 \mathrm{~s}$.

This paper examines the four measurements of $\mathrm{H}_{\mathrm{s}}$ and $\sigma^{0}$ available (TOPEX-K $\mathrm{K}_{\mathrm{u}}$, TOPEX-C, Jason- $\mathrm{K}_{\mathrm{u}} \&$ Jason-C) to contrast the inter-frequency differences with those between instruments. First I show an illustrative example, and look at the statistics of the differences in wave height and backscatter. Then I recap the definition of attenuation from dual-frequency $\sigma^{0}$ measurements, and compare the mean $\sigma^{0}-\sigma^{0}$ relationships for Jason and TOPEX, and of how they each depend upon wave height. Finally I assess the efficacy of the Jason rain flag, first vicariously using TOPEX, and then by examining its ability to remove anomalous data.

\section{Comparison of wave height and sigma0 data}

There are various papers (Ray \& Beckley, 2003; Zanife et al., 2003) that have already made some intercomparison of Jason and TOPEX $\mathrm{K}_{\mathrm{u}}$-band data. Such results are only repeated here in order to provide foundations for the inter-frequency comparison. For my analyses I solely use data from the TOPEX and Jason GDRs (Geophysical Data Records) rather than the IGDRs (Interim GDRs). The data span used here is Jason cycles 4 to 21 (corresponding to TOPEX cycles 347 to 364. [ Jason commenced collecting data on 15th Jan 2002 in cycle 1, but the first few cycles have not been used here. The single frequency Poseidon altimeter was operating for cycle 361, and the TOPEX/Poseidon satellite was moved to a new orbit with an interleaved ground track on August 15th, part way through cycle 365. ] The GDRs contain a radiometer-derived estimate of the atmospheric attenuation, which has already been applied to the $\sigma^{0}$ values; these corrections (for $\mathrm{K}_{\mathrm{u}^{-}}$and $\mathrm{C}$-band) are here removed so that all my analysis is with the observed values of $\sigma^{0}$. No other instrumental corrections were removed.

The $\sigma^{0}$ values reported on the Jason GDRs correspond to the current best understanding of the actual instrument measurement, and differ considerably from the TOPEX values. For the first release of the Jason IGDRs $-2.26 \mathrm{~dB}$ was added to the $\sigma_{\mathrm{Ku}}^{0}$ and $-0.28 \mathrm{~dB}$ to $\sigma_{\mathrm{C}}^{0}$ to make them consistent with TOPEX, but this has not been done for subsequent IGDRs or for the more widely-disseminated GDRs that I have chosen to use here. I have re-evaluated these corrections using TOPEX-Jason matchup pairs that have been extensively quality-controlled (see Table 1). There is some minor variation in the derived offsets with time (due to changes in one or the other instruments). An effective bias was determined independently for each cycle, with the mean offset being $-2.400 \mathrm{~dB}$ at $\mathrm{K}_{\mathrm{u}}$-band (with a std. dev. of $\pm 0.016 \mathrm{~dB}$ ) and $-0.725 \mathrm{~dB}$ (std. dev. $=0.029 \mathrm{~dB}$ ) at C-band. The precise values do depend somewhat on the quality control of the data (see appendix for an example). For most of this paper the Jason values are 'adjusted' to agree in the mean with those from TOPEX. This does not imply that the latter are 'correct', but makes it much easier for the comparison plots to show subtle differences between the two satellites. This allows one to demonstrate whether such a bulk adjustment is sufficient to generate a consistent TOPEX-Jason combined dataset. [ The TOPEX $\sigma^{0}{ }_{\mathrm{C}}$ values exceed $\sigma^{0} \mathrm{Ku}$ by $3.55 \mathrm{~dB}$ on average (and of course, the adjusted Jason values differ by that amount). In Fig. 2a, the TOPEX and adjusted Jason $\sigma^{0}{ }_{C}$ values have had $3.55 \mathrm{~dB}$ subtracted from them to demonstrate how closely changes in $\sigma_{\mathrm{Ku}}^{0}$ are mirrored 
in $\sigma_{C}^{0}$. For many of the other plots $\sigma_{C}^{0}$ is used along the abscissa (x-axis); in Fig. 5 the plot as a function of $\sigma_{\mathrm{Ku}}^{0}$ has been adjusted right by $3.55 \mathrm{~dB}$ for ease of comparison with the other curves. ]

\section{Example profile}

Figure 2 displays the near-simultaneous TOPEX and Jason data along a typical track. To compare the fine detail variations in $\sigma^{0}$, Jason values have been adjusted to agree with TOPEX, and then $3.55 \mathrm{~dB}$ removed from both C-band series. After such an adjustment the $\sigma^{0}$ profiles overlie one another closely despite variations in value of more than $10 \mathrm{~dB}$. Similarly the four measurements of wave height (Fig. 2b) agree well. The third set of graphs show a basic estimate of sea surface height ( $\mathrm{SSH}$, see caption for details); this simple definition is useful for comparisons without bringing in the complication of different wet tropospheric or sea state bias corrections for the two instruments. The fourth row shows a passive microwave brightness temperature (BT) as an indicator of possible rain.

The right-hand column focuses in on the data between $2.5^{\circ}$ and $5.5^{\circ} \mathrm{N}$ to reveal the differences between the Jason and TOPEX dual-frequency observations. Records at $2.7^{\circ} \mathrm{N}, 3.6^{\circ} \mathrm{N}$ and $4.8^{\circ} \mathrm{N}$ are all affected by rain (deduced from the sharp decrease in $\sigma^{0}{ }_{\mathrm{Ku}}$ and associated high BT values. All three of these features show concomitant spikes in $\mathrm{K}_{\mathrm{u}}$-band wave height and $\mathrm{SSH}$. I have examined a number of such case studies: in the majority the spikes in $\mathrm{SSH} \& \mathrm{H}_{\mathrm{s}}$ are more extreme for Jason than for TOPEX, but the disturbances are of no greater latitudinal extent. Jason average waveforms are retracked independently, whereas for TOPEX the values incorporate the effect of a smoothing filter. This on-board smoothing may explain TOPEX's reduced $\mathrm{H}_{\mathrm{s}}$ fluctuations in both rain-free and rain-affected areas. The anomalies will normally be positive in wave height and negative in $\mathrm{SSH}$, because of the manner in which rain directly at nadir affects the waveforms and the values derived from them (Guymer et al., 1995; Quartly, 1997). The effect on wave heights derived from C-band data is much weaker, and for TOPEX is mainly caused by the mispositioning of the C-band window due to a shift in the $\mathrm{K}_{\mathrm{u}}$-band tracker (Quartly, 1997). To quantify the magnitude of these data spikes I apply an 11-point running median to the $\mathrm{H}_{\mathrm{s}}$ data, and a 3-point running median to the SSH data and note how original values relate to these reference ones.

To make a quantitative comparison of the data from TOPEX and Jason, the observations need to be coregistered. The actual averaging interval for the data is not exactly one second - for TOPEX it is $1.073 \mathrm{~s}$, and for Jason 1.020s; consequently the separation of these nominal observation points varies (see Fig. 1). Using interpolation will reduce the size of the spikes shown in Fig. 2 and spread their effect over more points. Instead, I match up TOPEX and Jason points within $2 \mathrm{~km}$ of one another (which is small compared to the smeared one-second footprints that these observations represent). As well as these requirements on coincidence in time and space, some other checks are performed to end up with a quality-controlled dataset for comparison. These tests (see Table 1) are to avoid any occurrence of land or sea-ice within the altimetric footprint, and involve checks on the radiometer flags, that the ocean depth is greater than $1000 \mathrm{~m}$ and that the data are between $50^{\circ} \mathrm{S}$ and $50^{\circ} \mathrm{N}$ (the latter being a very conservative constraint). Also, in the initial work I needed data free from the effect of rain, so editing was also done according to BT from the microwave radiometers, waveform-derived mispointing and $\sigma_{\mathrm{h}}$ (the rms variation in range within a $1 \mathrm{~s}$ average). My full dataset of over-ocean matchups within $2 \mathrm{~km}$ contains about 300,000 paired observations per cycle; the stringent tests to remove any possibly anomalous data passed $\sim 62 \%$ of these points. Figure 3 shows the histograms for a 2-cycle period of data, both before and after the extra selection tests. These tests pass most points at low wave height and wind speed (high $\sigma^{0}$ ), but proportionally fewer for high sea state conditions. This is due to the removal of high latitude observations, and also the choice of fixed $\sigma_{\mathrm{Hs}}$ and $\sigma_{\mathrm{h}}$ thresholds, as the typical values of these measures increase with $\mathrm{H}_{\mathrm{s}}$ (see Fu et al., 1994 and Quartly, 2000a, for example). Use of all these tests discards too much data for ordinary applications, but that is acceptable for the present task of generating a TOPEXJason matchup dataset free from any likely effect of land, ice or rain. 


\section{Wave height comparison}

Figure 4a shows a scatter plot of a small selection of the matchup data for $\mathrm{K}_{\mathrm{u}}$-band estimates of $\mathrm{H}_{\mathrm{s}}$ from Jason and TOPEX. Using the full dataset, a mean difference between the two is calculated as a function of wave height, and also the spread (standard deviation) about this relationship noted. Four such comparisons are done, as shown in Figs. $4 \mathrm{~b}$ and c. The mean relationship between the two Ku-band estimates shows step changes at about $1.2 \mathrm{~m}, 3 \mathrm{~m}$ and $6 \mathrm{~m}$, which correspond to changes in the gate index used by TOPEX in calculating $\mathrm{H}_{\mathrm{s}}$. Within these ranges, polynomial expressions are used to determine $\mathrm{H}_{\mathrm{s}}$ from the measured waveform bins (Hayne et al., 1994); however, Quartly (2000a) showed there to be slight discontinuities in derived parameters across the boundary between different values of the gate index. Note that Jason's C-band values are biased high at low $\mathrm{H}_{\mathrm{s}}$; Zanife et al. (2003) noted that there was greater variability in Jason's measurements below about $1 \mathrm{~m}$.

Display in the form of Fig. $4 \mathrm{~b}$ reveals the non-linearities in the effects between the two measures of $\mathrm{H}_{\mathrm{s}}$, but assumes that all the errors are in the ordinate. I also fitted straight lines to the simultaneous data, allowing for equal errors in both estimates. This confirmed that TOPEX's $\mathrm{K}_{\mathrm{u}^{-}}$and C-band estimates are consistent (the trend in their difference is less than $0.2 \%$ ), and showed that Jason's $\mathrm{K}_{\mathrm{u}}$-band values are $1.8 \%$ less and it's C-band values $1.8 \%$ greater than the corresponding TOPEX ones. Using Jason IGDRs, Ray \& Beckley (2003) found Jason to be reading 3\% low relative to TOPEX at $\mathrm{K}_{\mathrm{u}}$-band; the slight difference in this trend observed in this work may be due to the use of GDR data here, or the effect of my editing criteria (Table 1), which have preferentially selected lower wave heights (Fig. 3a).

The third part of the figure shows the spread (standard deviation about the mean relationship) for each comparison. With the exception of the values for $\mathrm{H}_{\mathrm{s}}<1 \mathrm{~m}$, all four of the lines are approximated well by a straight line of slope 0.025 , with the lines involving TOPEX-K $\mathrm{K}_{\mathrm{u}}$ comparisons being approximately $0.2 \mathrm{~m}$ below those involving Jason-C band. [ The close-up in Fig. $2 b$ shows that Jason-C has much greater along-track variability than the other measures; on the other hand, it is the $\mathrm{K}_{\mathrm{u}}$-band channels that show occasional large anomalies in response to rain. ]

As part of the analysis to find the background $\mathrm{H}_{\mathrm{s}}$ value in the absence of rain, a running 11-point median filter was applied separately to all four $\mathrm{H}_{\mathrm{s}}$ estimates. A comparison of the four filtered sets of $\mathrm{H}_{\mathrm{s}}$ shows a similar mean relationship to that shown in Fig. 4b, but with the spread reduced by about a half, with the greatest proportional improvement for the comparison of the Jason pair and the least for the TOPEX pair (Fig. 4d). There are two factors involved here. First, the Jason C-band estimates are only based on 300 radar echoes in the collecting interval, so the effect of Rayleigh (fading) noise on its waveforms will be more pronounced that for the other three $\mathrm{H}_{\mathrm{s}}$ estimates. Second, the exact calculation of $\mathrm{H}_{\mathrm{s}}$ on TOPEX does involve some filtering beyond the 1s interval (see Quartly, 1997), so further filtering has less effect. For comparison with wave buoys, altimeter data are often averaged over scales of $60 \mathrm{~km}$ or more. The inter-instrument comparison in Fig. 4d, showing the agreement between two altimeters viewing the wave field $\sim 72 \mathrm{~s}$ apart, provides an estimate of the inherent repeatability of averaged altimetric values.

\section{Sigma0 comparison}

A similar analysis is carried out for the four $\sigma^{0}$ values. In this case, the Jason measurements of $\sigma_{\mathrm{Ku}}^{0}$ and $\sigma_{C}^{0}$ have been adjusted for a mean offset with respect to TOPEX. Figure 5a only shows the interinstrument comparisons, as the inter-frequency ones have a wide dynamic range, and are shown in Figs. 6 and 7. The C-band values agree to within better than $0.05 \mathrm{~dB}$ over most of the range. On the other hand, there is a marked change in the $\sigma_{\mathrm{Ku}}^{0}$ comparison. The 'reference sigma 0 ' on the abscissa corresponds to $\sigma_{\mathrm{Ku}}^{0}+3.55 \mathrm{~dB}$, this being the bulk offset between TOPEX's $\mathrm{K}_{\mathrm{u}}$-band and C-band. Thus the $\sigma_{\mathrm{Ku}}^{0}$ values agree to within $0.05 \mathrm{~dB}$ for $\sigma_{\mathrm{Ku}}^{0}<12.5 \mathrm{~dB}$ (corresponding to $90 \%$ of points in this edited matchup dataset), but are biased (Jason reading $\sim 0.15 \mathrm{~dB}$ higher than TOPEX) for $\sigma_{\mathrm{Ku}}^{0}>13.5 \mathrm{~dB}$. This disparity is curious, but has minimal effect upon retrieval of wind speed, as $\sim 90 \%$ of points are unaffected, and for those within the high $\sigma^{0}$ regime an error of $0.15 \mathrm{~dB}$ makes little difference to the derived wind speed. These $\sigma^{0}$ comparisons also show some variation with waveform-derived mispointing (see appendix), but the effect is slight within the range of data selected according to Table 1. 
The second plot of Fig. 5 shows the degree of mismatch between these near-simultaneous values. In the low $\sigma^{0}$ regime just discussed, covering $\sim 90 \%$ of observations, the Jason and TOPEX measurements have a spread about the mean of $\sim 0.1 \mathrm{~dB}$. This is an indicator of the limit on repeatability of $\sigma^{0}$ measurements. Intriguingly, the C-band estimates of the two instruments show a slightly greater consistency than the two $\mathrm{K}_{\mathrm{u}}$-band estimates. There are a number of possible explanations. This may be because TOPEX's C-band values do not have the wave height dependent adjustments that were applied to $\mathrm{Ku}$-band, or it may indicate that short-term changes in ocean backscatter or atmospheric attenuation are slightly greater at Ku-band than C-band. The inter-frequency comparisons are also shown in Fig. 5b. At the high wind speed end of the range $\left(\sigma^{0}{ }_{\mathrm{C}}<14 \mathrm{~dB}, \sigma_{\mathrm{Ku}}^{0}<10.5 \mathrm{~dB}\right)$ the standard deviation of the scatter about a mean relationship is about $50 \%$ higher for two different frequencies on the same altimeter than for the same frequency on two altimeters $\sim 72 \mathrm{~s}$ apart. This suggests that there are other factors than just wind speed affecting the $\sigma^{0}$ observation. However, for $\sigma_{C}^{0}$ in the range $14-19 \mathrm{~dB}$, the standard deviation of the mismatch between the two frequencies is similar to the mismatch between two altimeters. At even higher $\sigma^{0}$ there is a greater disparity between the two frequencies than between the nearly simultaneous measurements at the same frequency; however there are few observations in this regime.

\section{Definition of a dual-frequency rain flag for Jason}

The concept of a dual-frequency altimetric rain flag has been introduced in a number of papers, and so is only briefly recapped here. It is predicated on the generally tight relationship between $\sigma^{0}$ values at the two radar frequencies, with $\sigma_{\mathrm{Ku}}^{0}$ values significantly less than expected from the relationship being attributed to rain. The top panel of Fig. 6 shows 5000 observations (marked by crosses) from the edited (rain-free, land-free, ice-free) dataset for cycles 10 and 11. Statistics (mean and standard deviation) are calculated from all points in the edited dataset; the number of points per $0.05 \mathrm{~dB}$ bin is shown in Fig. $6 \mathrm{~b}$. The rain-flagging procedure involves testing whether points lie below some threshold, typically the mean minus $0.5 \mathrm{~dB}$ or the mean minus two standard deviations. (Discussion of the relative merits of these two choices is provided in Quartly et al., (1999).) In the example shown, both thresholds flag some points from within the selected quality dataset; however, it is not clear whether these thresholds are too strict or whether there were some rain-affected points within the edited dataset. Tournadre \& Morland (1997) advocate combining the dual-frequency test with one using data from the on-board microwave radiometer (MWR). This will help reduce false flagging of points, but may make the technique less sensitive to small rain cells.

\section{Comparison with mean $\sigma^{0}-\sigma^{0}$ relationship for TOPEX}

A comparison of the $\sigma^{0}-\sigma^{0}$ relationships for Jason and TOPEX show there to be some significant differences, which might not be expected given that both are portrayals of the equilibrium between sea surface roughness sensed at scales of $2.2 \mathrm{~cm}\left(\mathrm{~K}_{\mathrm{u}}\right.$-band) and $5.7 \mathrm{~cm}(\mathrm{C}$-band) under wind-only conditions. However, Fig. 5a has already shown there to be a $0.15 \mathrm{~dB}$ offset between Jason and TOPEX $\sigma_{\mathrm{Ku}}^{0}$ values at low winds. This difference in relationship must be due to differences between the instruments and/or their processing. One explanation might be that TOPEX is in error due to the known degradation of the point target response (PTR) and various power leakages (Hayne et al., 1994). However, the shape of the TOPEX-B mean $\sigma^{0}-\sigma^{0}$ relationship has changed little since its first operation in February 1999. Interestingly, the $\sigma^{0}-\sigma^{0}$ curve for early in the TOPEX-A operation has the same shape as TOPEX-B near the peak of the curve at $\sigma_{C}^{0}=15 \mathrm{~dB}$, but a gentler slope for high $\sigma^{0}$, more akin to that for Jason. (There is no discernible seasonal change in the $\sigma^{0}-\sigma^{0}$ curves, but later on in the TOPEX-A phase, the response at high $\sigma^{0}$ did change (Quartly, 2000b), presumably due to degradation of the PTR.)

In short, separate codings are required for the Jason and TOPEX rain flags, although they only represent different $\sigma^{0}-\sigma^{0}$ relationships due to presently unknown 'instrumental effects'. The scatter about the mean 
relationship is portrayed in Fig. 7b, with all three curves displaying the same form, but with Jason exhibiting the least scatter.

\section{Variation in $\sigma^{0}-\sigma^{0}$ relationship with time and wave height}

An important aspect of an operational dual-frequency rain flag is that the observed relationship between $\sigma_{\mathrm{Ku}}^{0}$ and $\sigma_{\mathrm{C}}^{0}$ should not vary rapidly. To test the consistency of the empirical $\sigma^{0}-\sigma^{0}$ relationship on short time scales, I took cycles 4-17 and divided each into fifths ( $\sim 2$ days), and only considered data with a wave height of $1.85 \mathrm{~m}$ to $2.15 \mathrm{~m}$ (because of a wave height dependency, discussed later). From these short selected sets of data, I determined independent $\sigma^{0}-\sigma^{0}$ relationships, albeit only over the range 14 to $17.5 \mathrm{~dB}$. All these curves have the same shape, but with r.m.s. offsets of $\sim 0.03 \mathrm{~dB}$ (in abscissa and/or ordinate) from one another. Fig. 7c shows the r.m.s. variations between the seventy 2-day estimates of the mean relationship: there is little spread $(\sim 0.03 \mathrm{~dB})$ at the peak of the $\sigma^{0}-\sigma^{0}$ curve, but wider variation on the flanks.

One approach to rain-flagging is to calculate separate mean relationships for each short interval of data: if the interval only contains 2 days of data, then the $\sigma^{0}-\sigma^{0}$ curve is poorly defined in the less wellpopulated regions. Alternatively, very large periods of data may be used in the definition: this suffers from variations in the mean relationship leading to a larger spread of values than are due to sea surface processes alone. For many studies (e.g. Quartly et al., 1996, Tournadre and Morland, 1997) a compromise has been to determine mean relationships and rain flagging independently for each 9.9-day cycle of data; however in this paper, a single relationship is used for all the cycles of the validation phase.

Elfouhaily et al. (1998) were the first to show that the $\sigma^{0}-\sigma^{0}$ curve has a wave height dependency at high $\sigma^{0}$. This was parameterized and incorporated in the rain flagging for TOPEX (Quartly et al., 1999). Here, I examine the effect within Jason data, using all the matchups from cycles 4 to 21 in order to have enough observations within each narrow $\mathrm{H}_{\mathrm{s}}$ bin. The divergence of the lines for high $\sigma^{0}$ (see Fig. $7 \mathrm{~d}$ ) is both qualitatively and quantitatively the same as for the contemporaneous TOPEX-B data, auguring that this is a real effect related to large scale waves affecting the small-scale waves sensed by these two frequencies. [ A similar wave height divergence at high $\sigma^{0}$ is found for the $\mathrm{K}_{\mathrm{u}}$ - and S-band observations of the Envisat RA-2 altimeter (Tournadre \& Quartly, 2003). ] The Jason observations show a wave height dependence to be present over the entire $\sigma^{0}$ range; this is not so clear for TOPEX data, but any true physical effect may be masked by the changes in corrections with gate index (Hayne et al, 1994).

The final Jason rain flag should have the wave height dependency taken into account, such that the derived attenuation, $\Delta \sigma^{0}$, is given by differencing the observed $\sigma_{\mathrm{Ku}}^{0}$ relative to an expected rain-free value that is both a function of $\sigma_{\mathrm{C}}^{0}$ and $\mathrm{H}_{\mathrm{s}}$, viz.:

$$
\Delta \sigma^{0}=\sigma_{\mathrm{Ku}}^{0}-\mathrm{F}\left(\sigma_{\mathrm{C}}^{0}, \mathrm{H}_{\mathrm{s}}\right)
$$

From a visual inspection of Fig. $7 \mathrm{~d}$, it appears this function can be separated into a simple $\sigma^{0}-\sigma^{0}$ relationship averaged over all $H_{s}$, plus an effect proportional to $H_{s}$ that applies to all $\sigma^{0}{ }_{C}$ values, plus an $\mathrm{H}_{\mathrm{s}}$ and $\sigma_{\mathrm{C}}^{0}$ dependent effect in the tail region (adjusted $\sigma_{\mathrm{C}}^{0}>16.4 \mathrm{~dB}$ ). Further work needs to be done on this in order to quantify fully the wave height dependency.

\section{Validation of Jason rain flag}

It is not easy to provide direct validation for Jason's rain flag. There have been two such exercises for the TOPEX rain flag. Cailliau \& Zlotnicki (2000) compared the latter to SSM/I data, showing moderate agreement. Their validation data had a much larger footprint than TOPEX ( $\sim 50 \mathrm{~km}$ versus $8 \mathrm{~km})$ and only coincided to within 30 minutes, which is a significant time in the evolution of rain cells. A more detailed study by McMillan et al. (2002) compared TOPEX with various ground-based radar networks. 
They showed that TOPEX can detect rain cells the size of its footprint. They also revealed much false flagging of events at high $\sigma^{0}$ values, which could be avoided by incorporation of a test using data from the microwave radiometer (MWR). As such exercises are very laborious, I here provide assessment of the Jason rain flag by two other methods: first by vicarious validation using TOPEX, and second by determining the efficacy of the Jason rain flag in discarding anomalous data.

\section{Comparison of dual-frequency rain flags}

The observed atmospheric attenuations, $\Delta \sigma^{0}$, are calculated independently for the two satellites using mean relationships appropriate for each. (In practice, this means there is no need for bulk adjustment of Jason $\sigma^{0}$ values to align with TOPEX distributions prior to the application of a rain-detection algorithm.) The validation via TOPEX is performed by comparing the two estimates of $\Delta \sigma^{0}$ (Fig. 8). An indication of their correspondence in setting a rain flag can be gleaned from the plot too. The majority of points correspond to $\Delta \sigma^{0}$ within $0.5 \mathrm{~dB}$ of zero for both TOPEX and Jason; however, there are sufficient points in each $0.5 \mathrm{~dB}$ bin to define a mean curve. The rain-related (negative) values of $\Delta \sigma^{0}$ show a clear correspondence, with the mean curve lying close to the line of equality; the scatter about that mean has a std. dev. of $\sim 0.6 \mathrm{~dB}$, but is much smaller at the origin, where the majority of observations are. There are also a number of observations for which $\Delta \sigma^{0}$ is significantly positive. Such 'inverse behaviour' was noted earlier for TOPEX (Quartly et al., 1996), with a possible explanation being damping of the smallest scale waves by recently-formed freshwater slicks. Chen et al. (1998) explored the effect for TOPEX; no further study of the effect is offered here, except to note that the values recorded by Jason are only about half of the magnitude of those for TOPEX, and that these points do not seem to correspond to particular wind speed or wave height conditions.

\section{Efficacy of a Jason rain flag}

Rain within the altimetric footprint distorts the waveforms from the expected 'ocean-like' returns, leading to anomalous values for the range, wave height and waveform-derived mispointing. Also, as some rain cells are significantly smaller than the distance travelled by the footprint in one second, there may be significant variability of the estimates of height, wave height and $\sigma^{0}$, given by $\sigma_{\mathrm{h}}, \sigma_{\mathrm{Hs}}$ and $\sigma\left(\sigma^{0}\right)$. The histograms of these six parameters are studied for cycles 10 and 11 (see Fig. 9). From the histograms for all data and for rain-flagged data, I determine the conditional probability of a point being contaminated by rain (grey lines, see right hand axes). [ Note, data displayed actually correspond to analysis for $\sigma^{0}{ }_{C}$ $\leq 17 \mathrm{~dB}$; observations with a high $\sigma^{0}$ (low wind speed) have a higher number of anomalous data, of which a lower fraction can be ascribed to the effect of rain. ]

The first three subplots show variability within the one second records. In all cases, at the mode of the histograms the association with rain is less than $1 \%$; however, large values of $\sigma_{\mathrm{h}}$ and $\sigma_{\mathrm{Hs}}$ and $\sigma\left(\sigma^{0}\right)$ are highly associated with rain, and so a dual-frequency rain flag would remove these points. If the analysis is repeated, but without the restriction that $\sigma^{0}$ be less than $17 \mathrm{~dB}$, then the use of a 'rain flag' alone does not remove all anomalous data. In that case, only around $15 \%$ of points with $\sigma\left(\sigma^{0}\right)>0.2 \mathrm{~dB}$ were detected by the rain flag; the proportion of high $\sigma_{\mathrm{Hs}}$ values selected by the rain flag was also reduced to $30-50 \%$. This implies that in such calm conditions there are factors other than rain leading to high variability within the 1 second averaging time. Conversely, it also means that for a single-frequency altimeter high values of $\sigma_{\mathrm{h}}$ and $\sigma_{\mathrm{Hs}}$ are not reliable indicators of rain (at least not in the high $\sigma^{0}$ regime).

The parameter $\psi^{2}$ represents the slope of the trailing edge of the waveforms. Positive values can be interpreted as the square of the mispointing (deviation of boresight from nadir). However, in general, it is used as an indicator of the waveform shape not conforming to the expected ocean-like returns. Extreme values of $\psi^{2}$ (both positive and negative) are probably associated with rain. The last two plots represent spikes in the height and wave height values. The height anomaly in Fig. 9e corresponds to the sea surface height at a point relative to a 3-point median centred on that point, and Fig. $9 \mathrm{f}$ is for wave height relative to an 11-point median. The dual-frequency rain falg picks out the majority of extreme 
height and wave height anomalies. Again, if the analysis incorporates very low wind conditions $\left(\sigma^{0}{ }_{C}\right.$ $>17 \mathrm{~dB}$ ), the proportion of large spikes in height and wave height attributable to rain is reduced to $\sim 30 \%$.

\section{Proportion of data flagged}

The proportion of data flagged as rain, and thus discarded by most users, will depend upon the particular editing criterion used, the threshold set and the geographical region of interest. On the whole, there is very little difference between a test using a specific attenuation value, $\Delta \sigma^{0}$, and one that relates this to a multiple of the varying measure of scatter as shown in Fig. 7b. This is because the majority of the data correspond to $\sigma_{C}^{0}<17 \mathrm{~dB}$, for which the scatter only varies gradually as a function of $\sigma^{0}$. Users who are particularly concerned about data flagging in low wind conditions will probably need to incorporate data from the MWR in their editing, although the section above showed that, in the high $\sigma^{0}$ regime there are a higher proportion of anomalous points due to some effect(s) other than rain.

Figure 10 shows in a global sense how the proportion of data flagged increases with the chosen threshold for $\Delta \sigma^{0}$; Table 2 shows appropriate thresholds according to the proportion of data that the user can tolerate losing. However, the proportion of points flagged clearly varies geographically according to the occurrence of rain. Figure 11 shows the proportion of data flagged according to $\Delta \sigma^{0}<-0.5 \mathrm{~dB}$, based on data from cycles 4 to 21 . The threshold specified here will not pick out drizzle and light rain; researchers wishing to use the rain flag for global or regional studies of rainfall may need to adopt a slightly different criterion (see Table 2) in order to optimise their recovery of rain events. For example, changing the $\Delta \sigma^{0}$ threshold to $-0.3 \mathrm{~dB}$ leads to a much higher proportion of rain around the edge of the Antarctic continent; it is not clear whether this is genuinely weak rain or moist snow or false flagging due to some slight disturbance to the mean $\sigma^{0}-\sigma^{0}$ relationship e.g. by freshwater slicks or slight inconsistencies in calibration (cf. Fig. 7c).

\section{Summary and discussion}

The near-simultaneous measurements of TOPEX and Jason during the verification phase have been important for comparisons of the range data from the two instruments, enabling detailed investigation of the correction terms (e.g. Zanife et al., 2003, Vincent et al., 2003). A similar analysis is provided here for sea state and rain information.

\section{Wave heights}

The example profile (Fig. 2) shows that the four wave height estimates (two altimeters, two independent frequencies) exhibit good general agreement, with the C-band values from Jason showing the largest along-track variability. That is partly due to the smaller number of pulses used in its calculation and the absence of any on-board temporal smoothing. Large spikes in $\mathrm{H}_{\mathrm{s}}$ are most common for Jason $\mathrm{K}_{\mathrm{u}}$-band. Waveform data have not been examined for this case, but it is likely that the distortions due to patchy attenuation will be similar for both TOPEX and Jason $\mathrm{K}_{\mathrm{u}}$-band waveforms. The increased prevalence and magnitude of spikes for Jason might indicate a greater sensitivity in its retracking to non-ocean-like waveforms. This is not of great concern, as such points are easily removed by the rain-flagging or by use of an along-track median filter.

Figure 4 provides the details of the comparison of the various estimates. Jason's wave heights are found to be $\sim 1.8 \%$ less than those calculated for TOPEX. Changes in the gate index used in the TOPEX wave height calculations are believed to explain some of the features in the curves detailing the mean differences (Fig. 4b). The standard deviation of the scatter about these mean curves increases linearly with wave height, apart from the increased scatter noted for $\mathrm{H}_{\mathrm{s}}$ less than $1 \mathrm{~m}$. Although all these points have been selected as rain-free, the use of an 11-point median filter does reduce the scatter by about a 
factor of two (Fig. 3d). This provides an indication of the repeatability of averaged altimeter wave height measurements for use in satellite-buoy comparisons.

Similar TOPEX-Jason comparisons and observations have already been reported (Ray \& Beckley, 2003, Vincent et al., 2003); what is particularly interesting in Fig. 3 is the comparison of the scatter of observations from one instrument at two frequencies to the scatter of observations from two instruments at the same frequency. The two lower curves in Figs. $4 \mathrm{c}, \mathrm{d}$ show that $\mathrm{H}_{\mathrm{s}}$ estimates at TOPEX's two frequencies agree as well as two measurements at $\mathrm{K}_{\mathrm{u}}$-band taken by different instruments. The Jason Cband values have larger along-track variability (Fig. 2), and consequently dominate all comparisons involving that channel (Figs. 4c,d).

\section{Backscatter strength and wind speed}

Although many users may be more concerned about the agreement in wind speed estimates based on the four channels, the comparison in Fig. 5 is in terms of $\sigma^{0}$, as this is the observed parameter, which is relevant for geophysical retrievals other than just wind speed, and is not dependent upon any particular wind speed algorithm. The $\sigma^{0}$ values for Jason are not just a simple offset from TOPEX (Fig. 5a); however, although the region for $\sigma_{\mathrm{Ku}}^{0}>12.5 \mathrm{~dB}$ ('reference sigma 0 ' $>16 \mathrm{~dB}$ ) occupies half the abscissa, it only represents the $10 \%$ of points with the lowest wind speeds.

The $\sigma^{0}$ values for TOPEX are calculated from an average over waveform bins 17-48 (Zieger et al., 1991), corresponding to a ground footprint of $\sim 8 \mathrm{~km}$ diameter (see Fig. 1); those for Jason are based on the maximum of an 8-bin running mean (O.-Z. Zanife, pers. comm., 2003). Low wind conditions tend to generate more specular waveforms (steeper trailing edges); the increase in $\sigma_{\mathrm{Ku}}^{0}$ bias between the two altimeters at high $\sigma^{0}$ may thus be a consequence of the different definitions employed. Certainly at higher $\sigma^{0}$ the bias also shows a greater dependence on waveform-derived mispointing (see appendix). Although this change in $\sigma_{\mathrm{Ku}}^{0}$ bias at low winds is detectable, it is insignificant in the calculation of wind speed.

In all comparisons there is greater variation in the high $\sigma^{0}$ regime. These observations correspond to generally low wind speeds, for which the correlation length is less than the diameter of the altimetric footprint. Consequently the $\sigma^{0}$ observations are an average over a number of patches with different surface roughness. This manifests itself by i) significant changes in both $\sigma^{0}{ }_{\mathrm{Ku}}$ and $\sigma_{\mathrm{C}}^{0}$ in the $\sim 72 \mathrm{~s}$ interval between the two altimeters' overflights, ii) large variability in the simultaneous measurements at two frequencies, and iii) large variation between neighbouring $\sigma^{0}$ observations. The relationship between the $\sigma_{\mathrm{Ku}}^{0}$ and $\sigma_{\mathrm{C}}^{0}$ values also shows a dependence on wave height, which can be explained as the large scale waves affecting the relative roughness at scales appropriate to $\mathrm{K}_{\mathrm{u}^{-}}$and $\mathrm{C}$-band radar scattering. Extended patches of high ocean backscatter have been termed 'sigma0 blooms' by Mitchum et al. (2004) who note that the condition occurs for $\sim 6 \%$ of TOPEX's deep ocean observations, with each typically extending over $150 \mathrm{~km}$ or more.

\section{Atmospheric attenuation and rainfall}

Separate algorithms for deriving atmospheric attenuation are required for TOPEX and Jason, because of both the large offset in their $\sigma^{0}$ values, and the slight change in the $\sigma_{\text {Ku }}^{0}$ bias at high $\sigma^{0}$ (Fig. 5a). There is some cycle-to-cycle variation (Fig. 7c), which means that for the most precise rain studies, it is advisable to calculate the $\sigma^{0}-\sigma^{0}$ relation independently for each cycle and instrument. However, the results presented in this paper are for a rain flag algorithm based on a synthesis of cycles 4 to 21 .

There is close agreement between the TOPEX and Jason determinations of $\Delta \sigma^{0}$ (Fig. 8). McMillan et al. (2002) have shown that for moderate to high winds the $\Delta \sigma^{0}$ calculated for TOPEX is, by itself, a reliable indicator of rain; but at high $\sigma^{0}$, large positive and negative values of $\Delta \sigma^{0}$ may arise in the absence of rain, with passive microwave observations needed to confirm the detection of rain. However, significant 
values of $\Delta \sigma^{0}$ are associated with altimetric anomalies irrespective of whether rain is their cause. Figure 9 demonstrates the usefulness of a simple dual-frequency rain flag for selecting the majority of points having variability within their $1 \mathrm{~s}$ averaging interval, and also those having anomalous values of $\psi^{2}, \mathrm{H}_{\mathrm{s}}$ or $\mathrm{SSH}$, which would all be associated with non-ocean-like waveforms. For high $\sigma^{0}$ values, there are many more anomalies not picked up by the rain flag, which may be due to patchiness in the reflectivity within the altimetric footprint. Some users recommend discarding all data with $\sigma_{\mathrm{Ku}}^{0}$ (TOPEX scaling) above about $13.5 \mathrm{~dB}$. An attenuation threshold of $0.5 \mathrm{~dB}$ below the mean $\sigma^{0}-\sigma^{0}$ relationship appears useful for most applications (discarding less than $1 \%$ of global data); Table 2 gives the appropriate thresholds for users with different data quality requirements.

In all, the verification phase has enabled close comparisons of $\mathrm{H}_{\mathrm{s}}, \sigma^{0}$ and $\Delta \sigma^{0}$ observations from the two altimeters, revealing subtle differences in their behaviour. The analysis of this paper should help the development of a consistent climatology of sea state and rain spanning the TOPEX and Jason missions.

\section{Appendix: Variation of perceived $\sigma^{0}$ with waveform-derived mispointing}

The difference between TOPEX and Jason near-simultaneous records of $\sigma^{0}$ is not a simple offset, but a function itself of the observed signal strength (Fig. 5a). This offset is also a function of $\psi^{2}$. This term is a measure of how much the slope of the trailing edge of the waveform differs from that expected for reflections from a directly nadir-pointing instrument over a rough homogeneous surface. This term is often referred to as 'mispointing' because pointing of the instrument away from nadir will lead to a flatter trailing edge, and thus positive values of $\psi^{2}$. However, other processes e.g. slicks, sea-ice or rain partially within the footprint, can lead to changes in the trailing edge slope.

The majority of observations have $\left|\psi^{2}\right|<0.04$, which is one of the editing criteria used in selection of anomaly-free data (Table 1). However, more extreme values of $\psi^{2}$ are associated with a change in the bias between Jason and TOPEX (Fig. A1). TOPEX determines $\sigma^{0}$ from the total of all the bins in the AGC gate (bins 17-48), whereas Jason uses the peak of an 8-bin running average across the waveform. Thus the steepest trailing edges $\left(\psi^{2}<0\right)$ should lead to proportionally higher $\sigma^{0}$ values for Jason, as shown in Fig. A1a. The C-band waveforms have a much flatter trailing edge (due to the larger antenna beamwidth at the lower frequency). The change in bias between TOPEX and Jason $\sigma_{C}^{0}$ values shows a similar dependence on $\psi^{2}$ for high values of $\sigma_{C}^{0}$, but no offset at low values. [ Note the lines in Fig. A1 are only drawn where there are sufficient data; thus $\psi^{2}<-0.10$ only occurs significantly for light to moderate winds (TOPEX $\sigma_{\mathrm{Ku}}^{0}>11.5 \mathrm{~dB}$ ), whereas $\psi^{2}>0.10$ is only associated with high winds. ]

From Fig. A1 it is not clear how much of the effect is due to TOPEX, and how much to Jason's processing. Plots of the $\sigma^{0}-\sigma^{0}$ relationship for Jason as a function of $\psi^{2}$ (not shown) imply that values of $\psi^{2}>0.05$ are associated with a relative shift between $\sigma_{\mathrm{Ku}}^{0}$ and $\sigma_{\mathrm{C}}^{0}$ of $\sim 0.2 \mathrm{~dB}$. Further work may be required to determine whether this is a processing artefact or whether such extremes of $\psi^{2}$ are associated with physical processes that affect the backscatter properties of the sea surface. Certainly, there are discrepancies between the TOPEX and Jason processing of such cases. 


\section{References}

Cailliau, D., and V. Zlotnicki. 2000. Precipitation detection by the TOPEX/Poseidon dual-frequency radar altimeter, TOPEX Microwave Radiometer, Special Sensor Microwave/Imager and climatological shipboard reports. IEEE Trans. Geosci. and Rem. Sensing 38: 205-213.

Chen G., B. Chapron, J. Tournadre, K. Katsaros, and D. Vandemark. 1998. Identification of possible wave damping by rain using TOPEX and TMR data. Rem. Sens. Envt. 63: 40-48.

Elfouhaily, T., D. Vandemark, J. Gourrion, and B. Chapron. 1998. Estimation of wind stress using dualfrequency TOPEX data. J. Geophys. Res. 103: 25101-25108.

Fu, L-L. et al. 1994. TOPEX/POSEIDON mission overview. J. Geophys. Res. 99: 24369-24381.

Guymer T.H., G.D. Quartly, and M.A. Srokosz. 1995. The effects of rain on ERS-1 radar altimeter data. J. Atmos. Oceanic Tech. 12: 1229-1247.

Hayne, G.S., D.W. Hancock, C.L. Purdy, and P.S. Callahan. 1994. The corrections for significant wave height and attitude effects in the TOPEX altimeter. J. Geophys. Res. 99: 24941-24955.

McMillan, A.C., G.D. Quartly, M.A. Srokosz, and J. Tournadre. 2002. Validation of TOPEX rain algorithm: Comparison with ground-based radar. J. Geophys. Res. 107 (D4): 3.1-3.10. (DOI 10.1029/2001JD000872)

Mitchum G.T., D.W. Hancock, G.S. Hayne, and D.C. Vandemark. 2004. $\sigma^{0}$ blooms in the TOPEX radar altimeter data. to appear in J. Atmos. Oceanic Tech.

Quartly G.D. 1997. Achieving accurate altimetry across storms: Improved wind and wave estimates from C-band. J. Atmos. Oceanic Tech. 14: 705-715.

Quartly G.D. 2000a. On the gate-dependence of geophysical retrievals from the TOPEX altimeter. J. Atmos. Oceanic Tech. 17: 1247-1251.

Quartly G.D. 2000b. Monitoring and cross-calibration of altimeter $\sigma^{0}$ through dual-frequency backscatter measurements. J. Atmos. Oceanic Tech. 17: 1252-1258.

Quartly G.D., T.H. Guymer, and M.A. Srokosz. 1996. The effects of rain on Topex radar altimeter data. J. Atmos. Oceanic Tech. 13: 1209-1229.

Quartly G.D., M.A. Srokosz, and T.H. Guymer. 1999. Global precipitation statistics from dual-frequency TOPEX altimetry. J. Geophys. Res. 104: 31489-31516.

Quartly G.D., M.A. Srokosz, and T.H. Guymer. 2000. Changes in oceanic precipitation during the $1997-$ 98 El Niño. Geophys. Res. Lett. 27: 2293-2296.

Ray, R.D., and B.D. Beckley. 2003. Simultaneous ocean wave measurements by the Jason and Topex satellites, with buoy and model comparisons. Marine Geodesy 26, 367-382.

Srokosz, M.A., and T.H. Guymer. 1988. A study of the effect of rain on Seasat radar altimeter data. Proc. of IGARSS '88: 651-654.

Tournadre, J., and J.C. Morland. 1997. The effects of rain on TOPEX/POSEIDON altimeter data. IEEE Trans. Geosci. and Rem. Sensing 35: 1117-1135.

Tournadre, J., and G.D. Quartly. 2003. Validation of Envisat RA2 rain flag. IFREMER Tech. Rept. DRO-OS No. 03/01, 12pp.

Vincent P. et al. 2003. Jason-1 geophysical performance evaluation. Marine Geodesy 26, 167-186.

Witter, D.L., and D.B. Chelton. 1991. A Geosat altimeter wind speed algorithm and a method for altimeter wind speed algorithm development. J. Geophys. Res. 96: 20275-20285.

Zanife, O.Z. P. Vincent, L. Amarouche, J.P. Dumont, P. Thibaut, and S. Labroue. 2003. Comparison of the Ku-band range noise level and the relative sea state bias of the Jason-1, TOPEX and POSEIDON-1 radar altimeters. Marine Geodesy 26, 201-238.

Zieger, A.R., D.W. Hancock, G.S. Hayne, and C.L. Purdy. 1991. NASA radar altimeter for the TOPEX/POSEIDON project. Proc. IEEE 79: 810-826. 


\section{Tables \& Figures}

Table 1 : Editing criteria used to generate a dataset free from contamination by land, ice or rain. ( $\mathrm{T}$ indicates test applied to TOPEX data; J - to Jason data.)

\begin{tabular}{|l|l|}
\hline Parameter & Test for keeping points \\
\hline Topography $($ depth), $\mathrm{d}$ & $\mathrm{d}<-1000 \mathrm{~m}$ \\
\hline Latitude, $\phi$ & $-50^{\circ}<\phi<50^{\circ}$ \\
\hline T: R.m.s. of range, $\sigma_{\mathrm{h}}$ & $\sigma_{\mathrm{h}}<0.08 \mathrm{~m}$ \\
\hline J: R.m.s. of range, $\sigma_{\mathrm{h}}$ & $\sigma_{\mathrm{h}}<0.13 \mathrm{~m}$ \\
\hline T: R.m.s. of wave height, $\sigma_{\mathrm{Hs}}$ & $\sigma_{\mathrm{Hs}}<0.12 \mathrm{~m}$ \\
\hline $\mathrm{J}:$ R.m.s. of wave height, $\sigma_{\mathrm{Hs}}$ & $\sigma_{\mathrm{Hs}}<1.00 \mathrm{~m}$ \\
\hline T: Waveform-derived mispointing, $\psi$ & $\psi<0.22^{\circ}$ \\
\hline $\mathrm{J}:$ Waveform-derived mispointing, $\psi^{2}$ & $-0.04<\psi^{2}<0.04^{\circ}$ \\
\hline T: Brightness temperature at $18 \mathrm{GHz}, \mathrm{BT}_{18}$ & $\mathrm{BT}_{18}<180 \mathrm{~K}$ \\
\hline $\mathrm{J}:$ Brightness temperature at $18 \mathrm{GHz}, \mathrm{BT}_{18}$ & $\mathrm{BT}_{18}<180 \mathrm{~K}$ \\
\hline
\end{tabular}

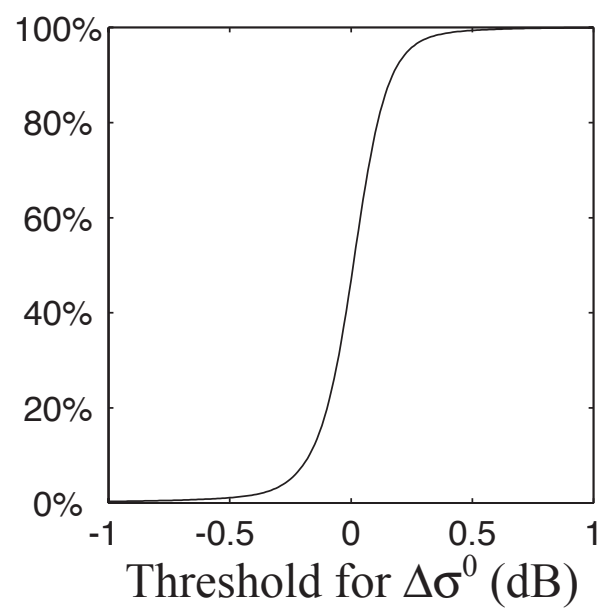

Figure 10 : Cumulative probability of observed atmospheric attenuation exceeding a threshold (Cycles 10 and 11 used here.)
Table 2 : Global proportions of data flagged according to various thresholds (based on cycles 10 and 11) [ Note proportions will change if MWR test also applied. ]

\begin{tabular}{|c|l|l|}
\hline $\begin{array}{l}\text { \% of data } \\
\text { to } \\
\text { be } \\
\text { flagged }\end{array}$ & $\begin{array}{l}\Delta \sigma^{0} \\
\text { threshold } \\
(\mathrm{dB})\end{array}$ & $\begin{array}{l}\text { Multiple } \\
\text { of } \\
\text { scatter, } \\
\mathrm{s}\left(\sigma_{\mathrm{C}}^{0}\right)\end{array}$ \\
\hline 0.5 & -0.80 & -5.64 \\
\hline 1 & -0.53 & -3.74 \\
\hline 2 & -0.37 & -2.69 \\
\hline 3 & -0.31 & -2.26 \\
\hline 5 & -0.25 & -1.83 \\
\hline 10 & -0.17 & -1.31 \\
\hline
\end{tabular}




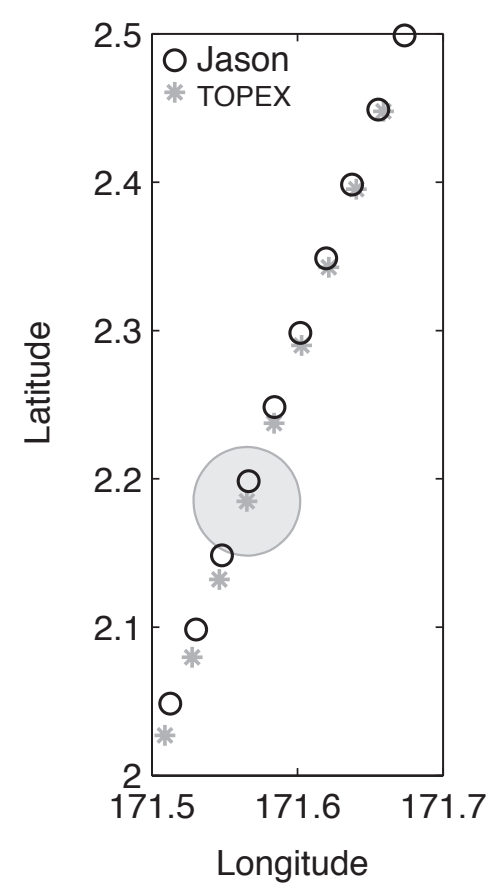

Figure 1 : Location of nominal '1 second' averages along track 123, for cycle 10 for Jason and corresponding cycle 353 for TOPEX. Circle ( $8 \mathrm{~km}$ in diameter) indicates size of instantaneous AGC footprint for TOPEX.

Figure 2 (next page)
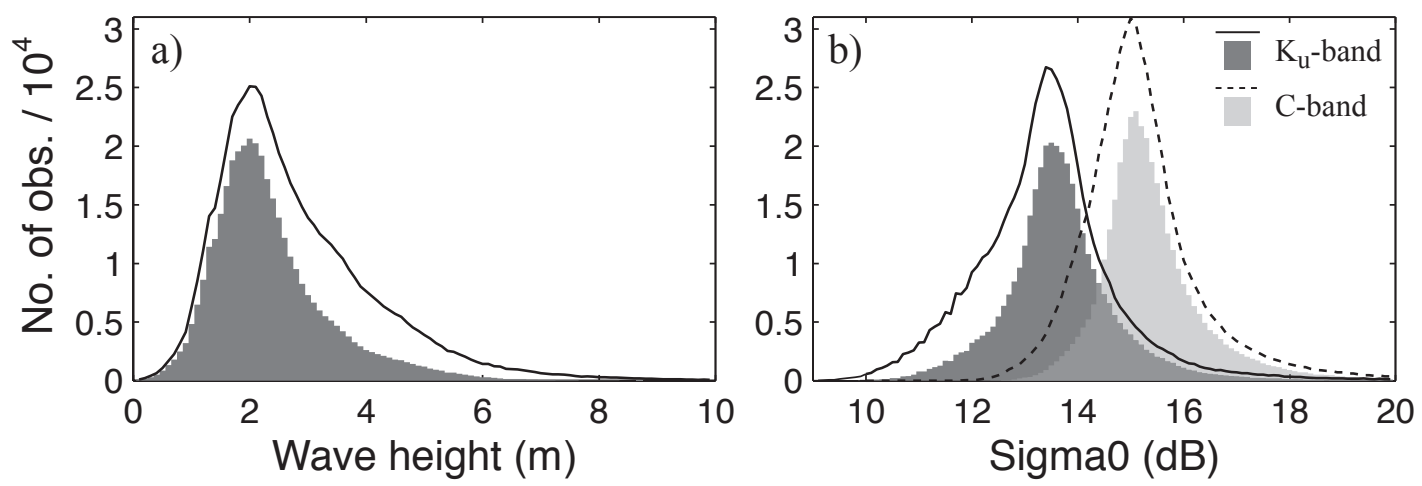

Figure 3 : Histograms of Jason's $H_{s}$ and $\sigma^{0}$ values for TOPEX-paired observations in cycles 10 and 11. Lines give number of points per bin for full matchup dataset; shaded region is for those also passing the data editing tests listed in Table 1. a) $\mathrm{K}_{\mathrm{u}}$-band value of $\mathrm{H}_{\mathrm{s}}$ in $0.1 \mathrm{~m}$ bins. b) $\mathrm{K}_{\mathrm{u}}$ - and C-band values of $\sigma^{0}$ in $0.1 \mathrm{~dB}$ bins. (Jason values not adjusted to match TOPEX.) 

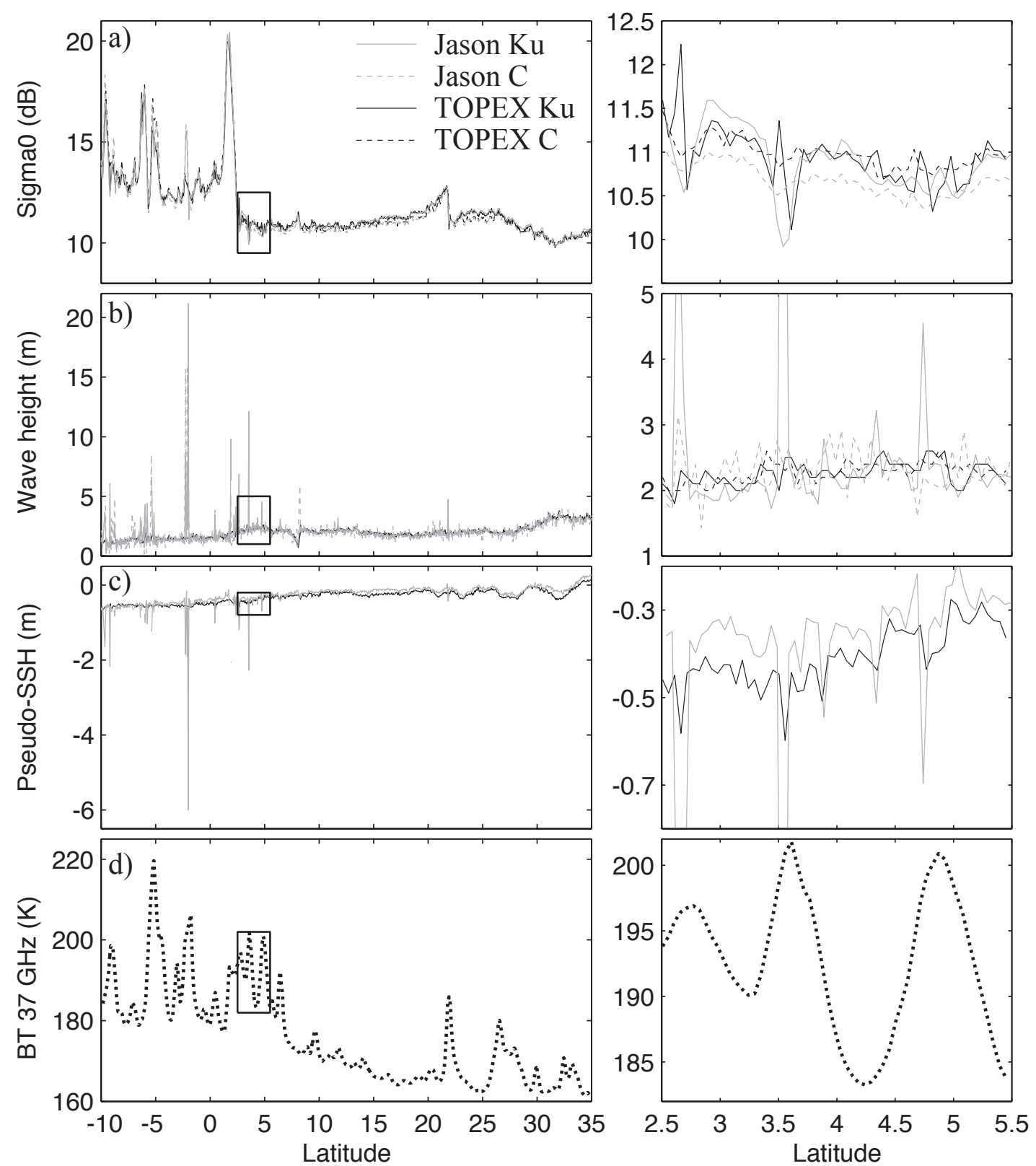

Figure 2 : Comparison of various parameters for near-simultaneous TOPEX and Jason data along pass 225 (cycle 6 for Jason, cycle 349 for TOPEX). Right-hand column shows in finer detail the variation within the marked boxes in the left hand column. a) Sigma0 (with bulk adjustment of Jason as discussed in text and $3.55 \mathrm{~dB}$ subsequently removed from $\mathrm{C}$-band values to overlie $\mathrm{K}_{\mathrm{u}}$-band values), b) Wave height, c) Pseudo-SSH (which is orbit minus range with only dry tropospheric correction applied), d) 37 $\mathrm{GHz}$ brightness temperature from the TMR. 

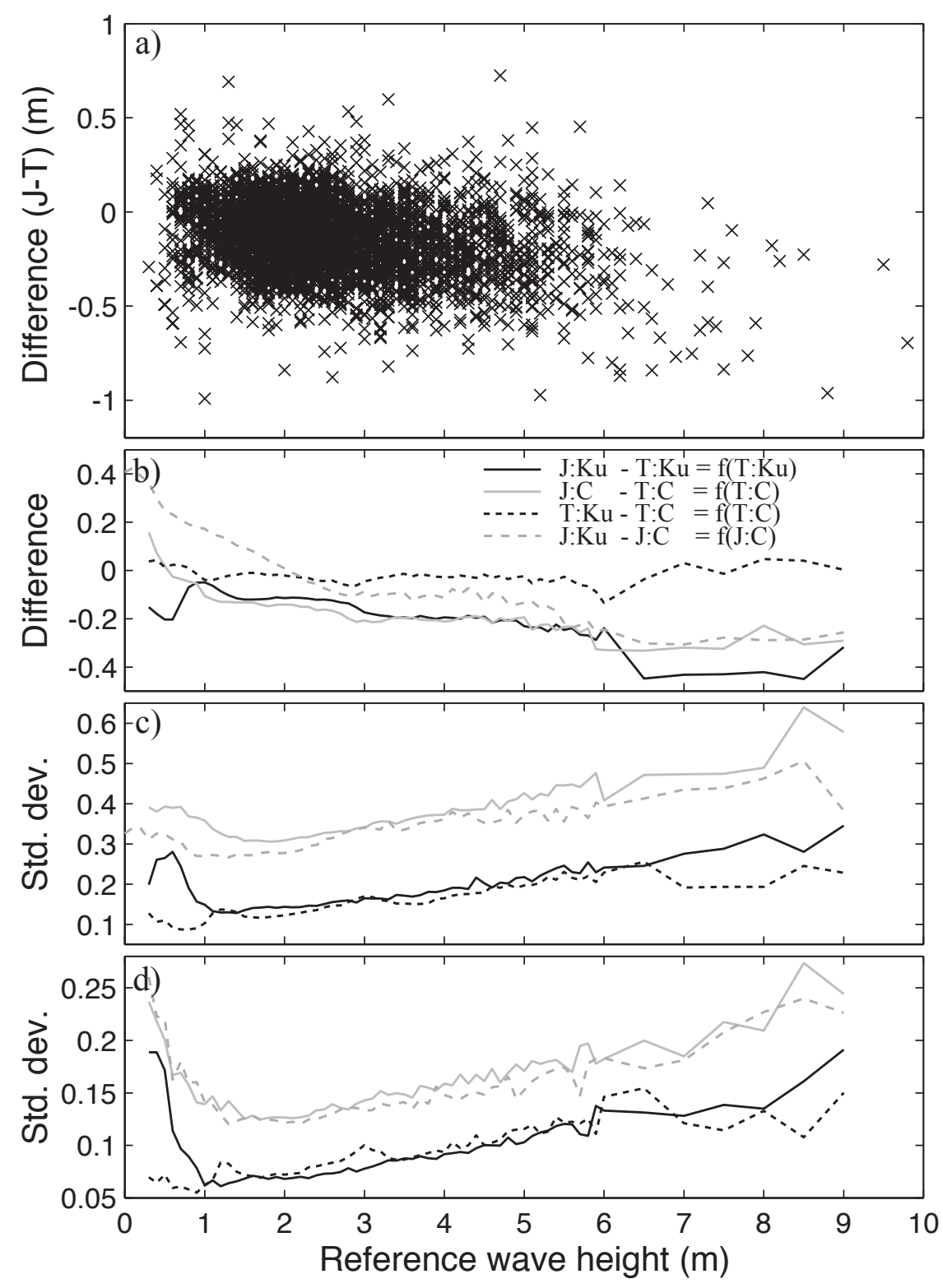

Figure 4 : Intercomparison of $\mathrm{K}_{\mathrm{u}^{-}}$and C-band wave height data from TOPEX and Jason. a) Scatter plot of difference between Jason and TOPEX $K_{u}$ records against TOPEX $K_{u}$-band values. b) Mean difference as a function of wave height. c) Standard deviation of difference of $1 \mathrm{~Hz}$ values. d) Standard deviation of running 11-point median. [ Data are from Jason cycles 10 and 11, with top plot only showing a subset of the points used in the analysis. Interpretation of lines in b), c) and d) is given by key in b), where solid black line represent Jason- $K_{u}$ minus TOPEX-K $K_{u}$ plotted as a function of TOPEX-K $K_{u}$ etc. ] 


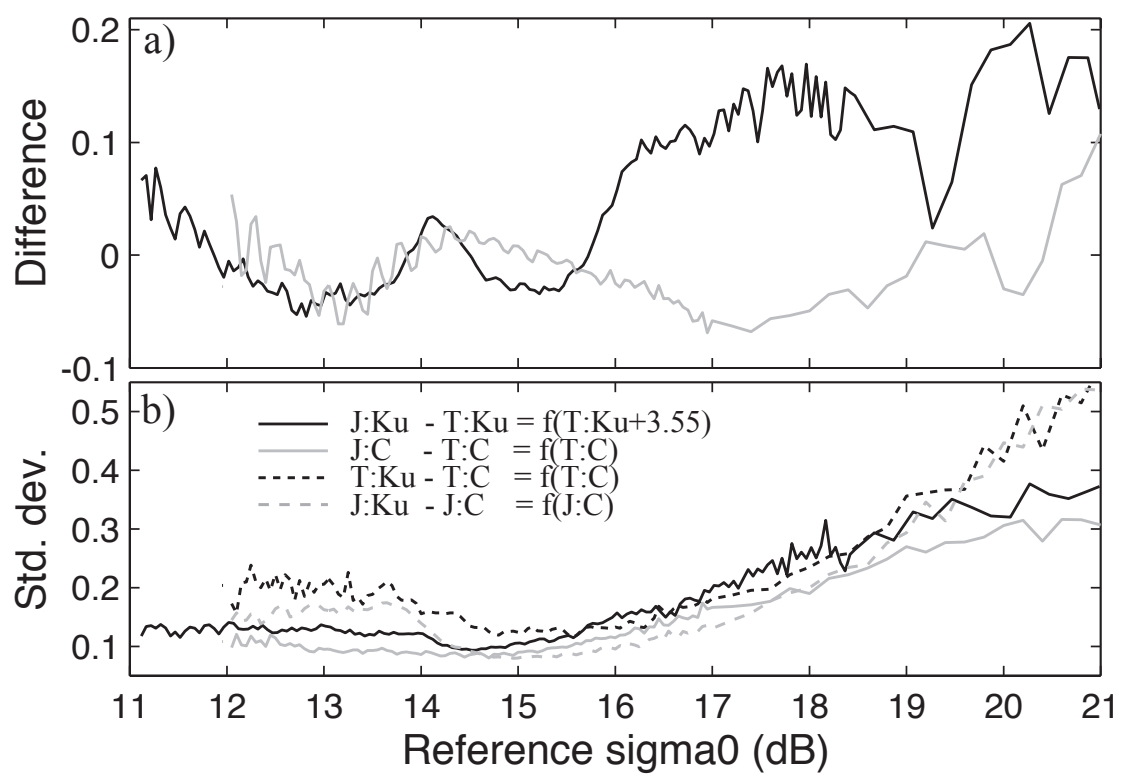

Figure 5 : Intercomparison of $\mathrm{K}_{\mathrm{u}^{-}}$and C-band $\sigma^{0}$ data from TOPEX and Jason. a) Mean difference. b) Standard deviation of difference. [ Cycles of data and labelling are as for Fig. 4, except all Jason data have been adjusted by mean $\sigma^{0}$ difference between Jason and TOPEX. ]

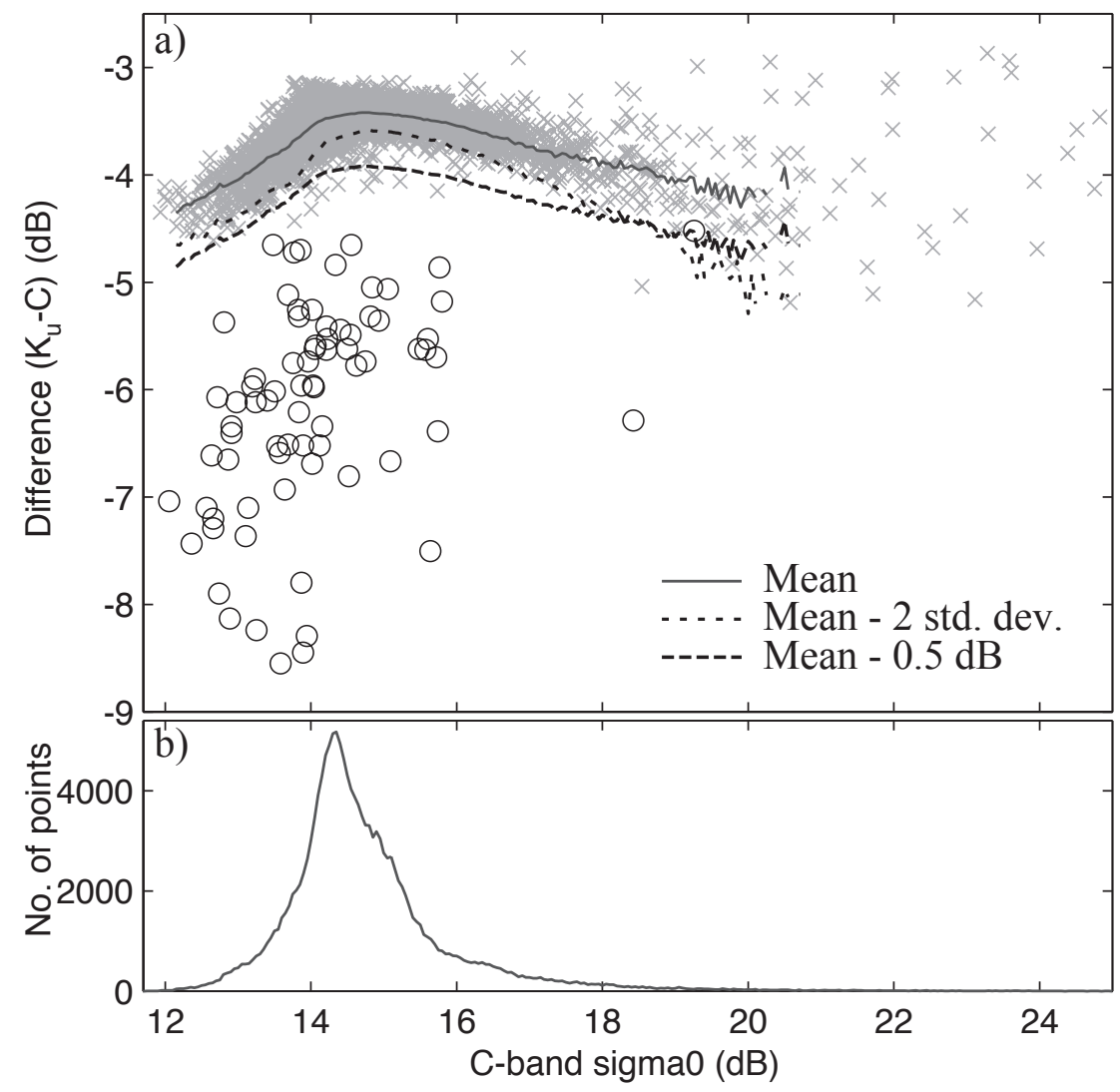

Figure 6 : Definition of a dual-frequency rain flag for Jason. (The $\sigma^{0}$ values from the Jason GDRs have had their atmospheric correction removed and a bulk adjustment applied to agree in the mean with TOPEX.) a) Scatter plot of difference between $\sigma^{0}{ }_{\mathrm{Ku}}$ and $\sigma_{\mathrm{C}}^{0}$ against $\sigma^{0}$. Crosses indicate 5000 points sampled from cycles 10 and 11; added lines are calculated from all available data from these two cycles. The circles show 75 points believed to be strongly affected by rain (according to BT and $\sigma_{\mathrm{h}}$ values). b) No. of observations in each $0.05 \mathrm{~dB}$ bin. 

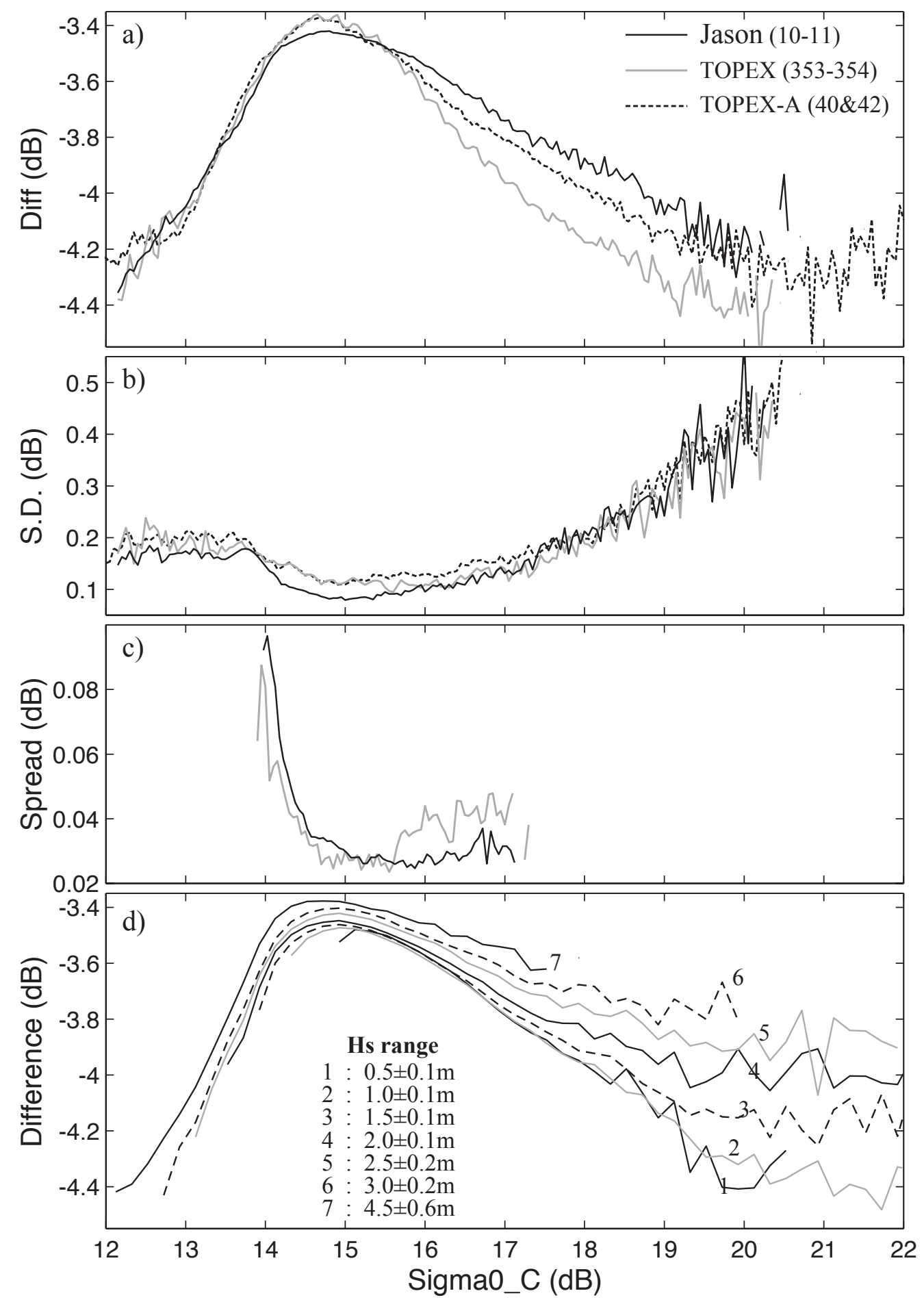

Figure 7 : Comparison of the $\sigma^{0}-\sigma^{0}$ relationships for Jason and TOPEX (after Jason values adjusted to agree in the mean with TOPEX). a) Mean relationships (including curve for early in TOPEX-A mission). b) Standard deviation about mean. c) R.m.s. variation of the mean profiles calculated independently from 70 two-day subsets. d) Wave height dependency of $\sigma^{0}-\sigma^{0}$ relationship for Jason. 


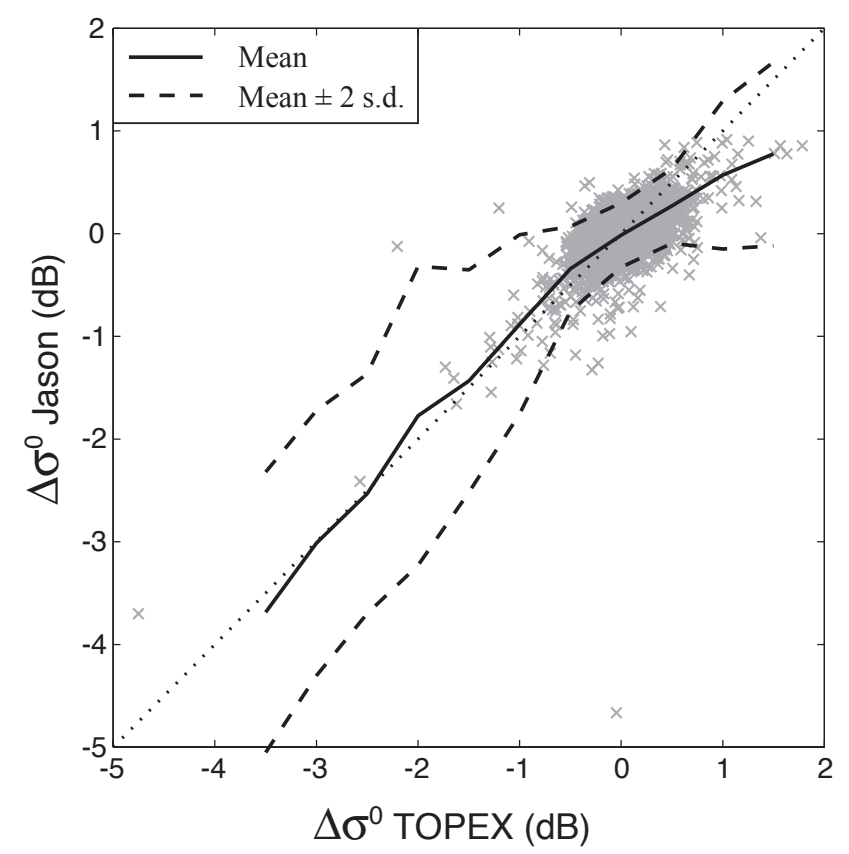

Figure 8 : Comparison of atmospheric attenuation, $\Delta \sigma^{0}$, derived independently from TOPEX and Jason data. Crosses indicate a subset of points from cycles 10 and 11; mean and std. dev. are calculated in bins of width $0.5 \mathrm{~dB}$ using all data from these 2 cycles.
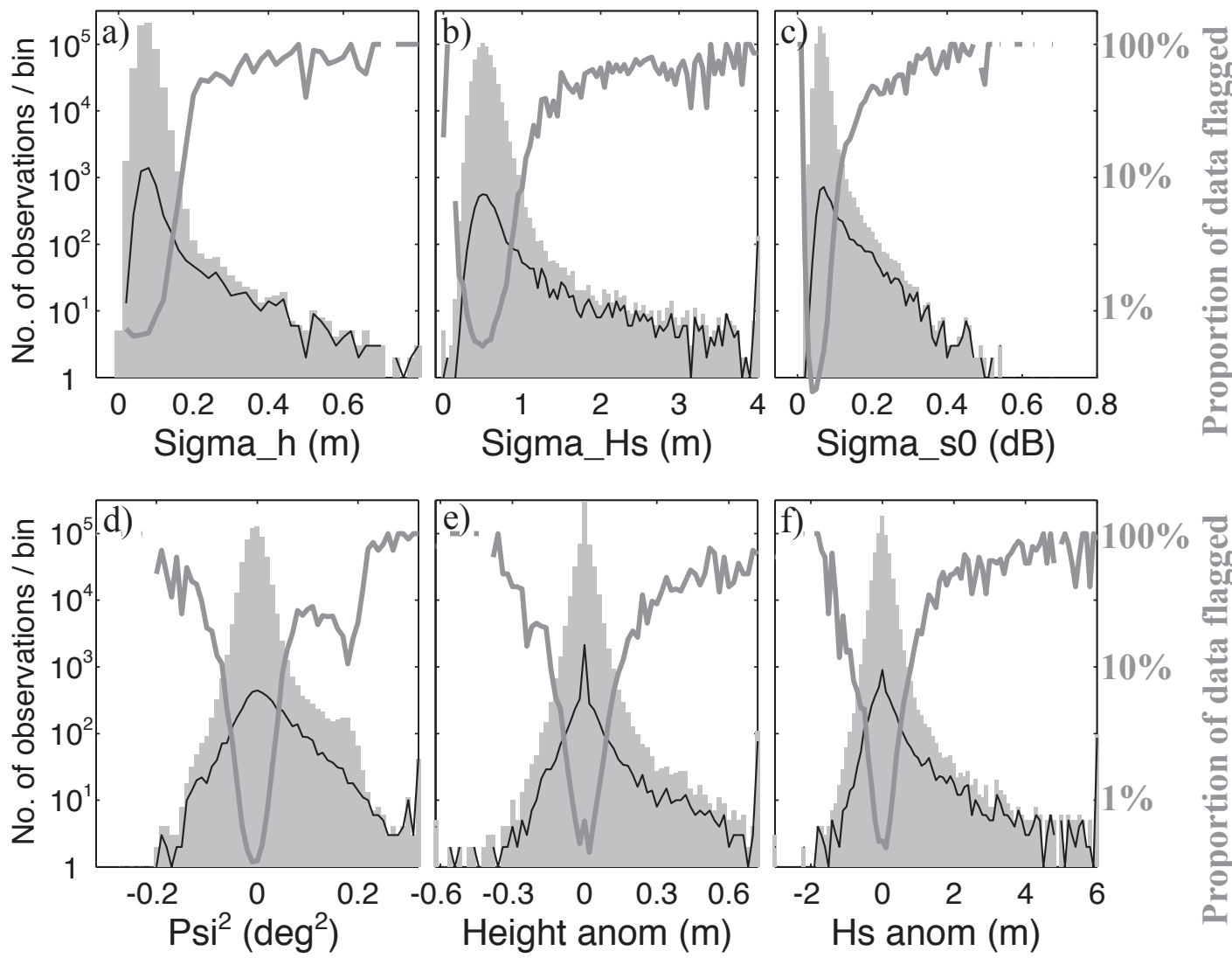

Figure 9 : Plots relating rain-flagging to other possible measures of data quality. Shaded region indicates histogram of all points in cycles 10 and 11 (note logarithmic axes); dark line shows histogram of those flagged as rain by the dual-frequency technique. The thick grey line shows proportion of points flagged as rain (according to logarithmic axes on right hand side). All plots relate to Jason $\mathrm{K}_{\mathrm{u}}$-band data, with very low winds $\left(\sigma^{0}{ }_{C}>17 \mathrm{~dB}\right)$ discarded, and the rain-flagging criterion $\left(\Delta \sigma^{0} \leq-0.5 \mathrm{~dB}\right)$ selecting $0.85 \%$ of the data. 
Figure 10 : Cumulative probability of observed atmospheric attenuation exceeding a threshold (Cycles 10 and 11 used here.) - Figure placed next to Table 2.

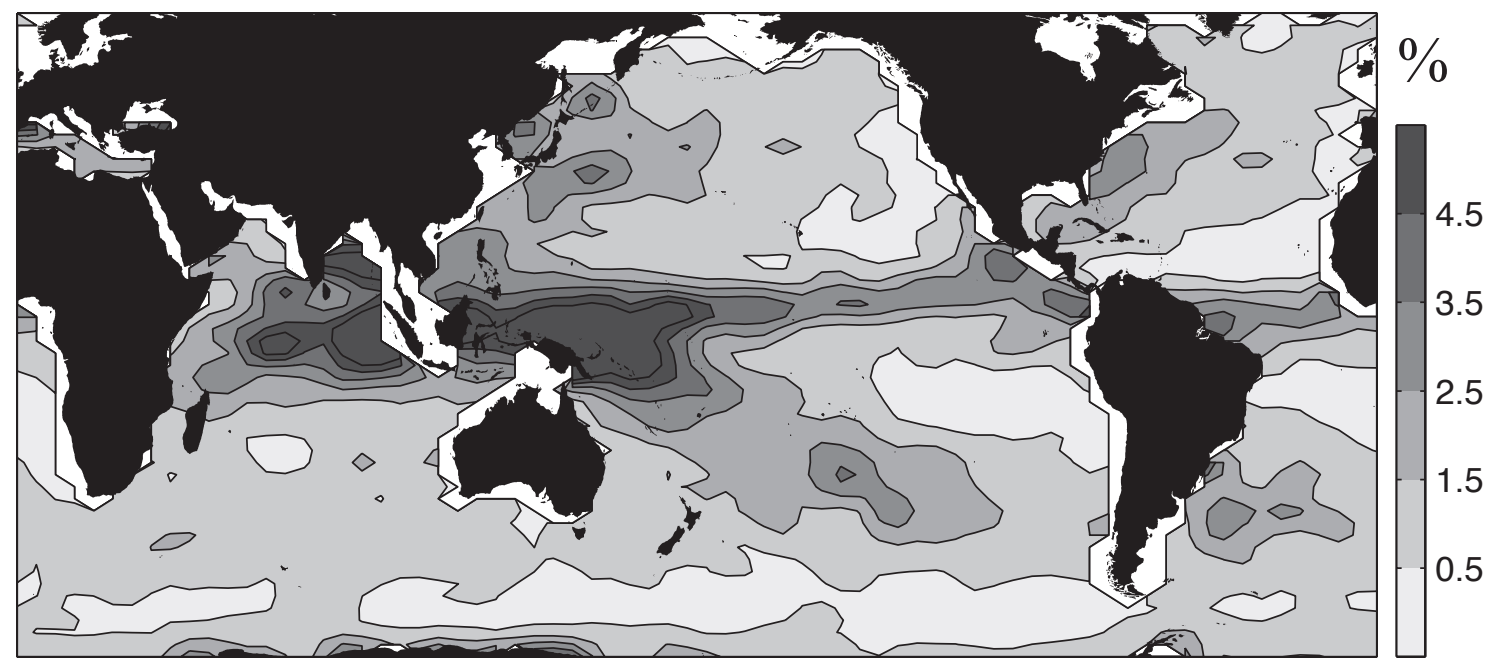

Figure 11 : Geographical distribution of data flagged as rain, according to $\Delta \sigma^{0} \leq-0.5 \mathrm{~dB}$. Data are from cycles 4 to 21 , of which $1.3 \%$ exceeds the threshold. (Some spatial smoothing has been applied to improve display.)
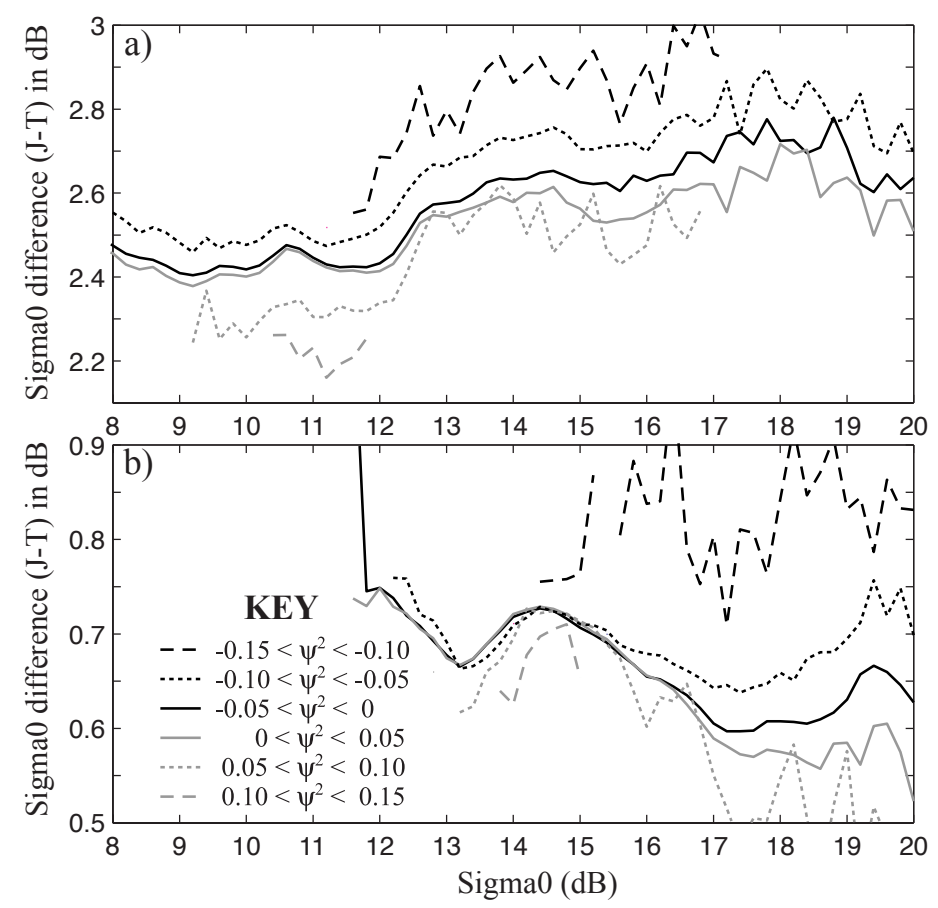

Figure A1 : Changes in $\sigma^{0}$ offset between Jason and TOPEX as a function of Jason's waveform-derived mispointing, $\psi^{2}$. a) $\mathrm{K}_{\mathrm{u}}$-band, b) C-band. 